\title{
THE INFLUENCE OF BRAND IMAGE AND PRODUCT QUALITY CONCERNING AUTOMOBILE BUYING DECISION OF ISUZU PANTHER AT PT. ASTRA ISUZU SEMARANG
}

\author{
Ardhi Wahyu Saputra, Dinalestari P. \\ Jurusan Administrasi Bisnis, Universitas Diponegoro Semarang, Indonesia \\ Email: janis@undip.ac.id
}

\begin{abstract}
Tranport equipment is badly needed in this era of fast-paced as it is, particularly cars. Competition in the automotive world is so tight. Therefore, businesses are required to be able to increase sales in order to survive in the business worlds. Specifically, this research was discuss about automobile buying of Isuzu Panther brand at PT Astra Isuzu Semarang during 2012-2015 keep have sale descending. If that case wasn't improve and solve, probably will presense problem for PT. Astra Isuzu Semarang next.

Aim of this research was to found brand image and product quality concerning automobile buying decision of Isuzu Panther Semarang. This research type was explanatory, with data collection technique by questionaire. The population in this research is consemers who use and bought Isuzu Panther automobile on PT Astra Isuzu Semarang with the number of samples taken was 72 respondents. Sampling using purposive sampling technique. Measurement scale using Likert scale. The analytical method used is the determination, simple linear regression, multiple liniear regression, $t$-test, and F-test using SPSS program version 16.

Based on the results of the research, revealed that the partially, brand image and product quality has positive influence on the purchasing decision which is indicated by result of the value of $t$ test bigger than t table. Significantly, variable brand image and product quality has positive influence towards purchasing decision indicated by value of $F$ test larger than F table.

And the advice that can be given is keeping a good image with a way keep it always communicate with consumers and customers. Besides continuing and improving product quality as well as improving its shortcomings, adding interior and exterior facilities and applying innovation to its products so as not to have the impression of monotonous and outdat
\end{abstract}

Alat transportasi merupakan hal yang sangat dibutuhkan di era serba cepat seperti sekarang ini, khususnya mobil. Persaingan di dunia otomotif pun begitu ketat. Oleh sebab itu, para pelaku bisnis harus mampu meningkatkan penjualan agar dapat bertahan didunia bisnis ini. Secara khusus penelitian ini membahas mengenai pembelian mobil merek Isuzu Panther PT. Astra Isuzu Semarang yang selama tahun 2012-2015 terus mengalami penurunan penjualan. Apabila hal tersebut tidak diperbaiki dan diatasi bukan tidak mungkin akan menimbulkan masalah bagi PT. Astra Isuzu Semarang kedepannya.

Tujuan penelitian ini adalah untuk mengetahui pengaruh citra merek dan kualitas produk terhadap keputusan pembelian mobil merek Isuzu Panther Semarang. Tipe penelitian ini adalah explanatory research, dengan teknik pengumpulan data melalui kuesioner. Populasi dalam penelitian ini yaitu konsumen pemakai atau pembeli mobil Isuzu Panther PT. Astra Isuzu Semarang dengan jumlah sampel yang diambil adalah 72 responden. Pengambilan sampel menggunakan teknik purposive sampling. Skala pengukurannya menggunakan skala Likert. Metode analisis yang digunakan adalah uji determinasi, regresi linier sederhana, regresi linier berganda, uji $\mathrm{t}$, dan uji $\mathrm{F}$ dengan program SPSS versi 16.

Berdasarkan hasil penelitian diketahui bahwa secara parsial, citra merek dan kualitas produk berpengaruh positif terhadap keputusan pembelian ditunjukkan dengan nilai $\mathrm{t}$ hitung lebih dari $\mathrm{t}$ tabel. Secara signifikan, variabel citra merek dan kualitas produk berpengaruh porsitif ditunjukkan dengan nilai $\mathrm{F}$ hitung lebih besar dari F tabel.

Saran yang dapat diberikan yaitu menjaga citra yang baik dengan cara tetap selalu berkomunikasi dengan konsumen maupun pelanggan. Selain itu, mempertahankan dan peningkatan kualitas produk serta memperbaiki kekurangan-kekurangannya, menambah fasilitas interior dan ekterior dan menerapkan inovasi terhadap produk-produknya agar tidak memiliki kesan monoton dan ketinggalan jaman.

Keywords

Marketing, Brand Image, Product Quality and Purchase Decision

Pemasaran, Citra Merek, Kualitas Produk, dan Keputusan Pembelian 


\section{Pendahuluan}

Kebutuhan sarana transportasi merupakan kebutuhan masyarakat yang terus berkembang sejalan dengan semakin tingginya mobilitas masyarakat dan meningkatnya taraf kehidupan ekonomi masyarakat. Salah satu alat transportasi modern adalah mobil. Mobil merupakan jenis kendaraan bermotor roda empat yang telah mengalami perkembangan, selain fungsinya sebagai alat transportasi tetapi juga dapat melindungi diri dari panas maupun hujan serta memberi kenyamanan bagi pengendaranya. Perkembangan pesat industri otomotif di Indonesia membuat tingkat persaingannya menjadi ketat, khususnya pada industri mobil Oleh karena itu perusahaan dituntut untuk memahami keinginan dan kebutuhan konsumennya serta untuk mempengaruhi keputusan pembelian. Menurut Kotler \& Amstrong (2008: 226) keputusan pembelian adalah tahap dalam proses pengambilan keputusan pembeli dimana konsumen benar-benar membeli. Untuk hal ini konsumen lebih ditekankan oleh bagaimana cara mendapatkan informasi tentang produk atau merek tertentu dengan membandingkan atau mengevaluasi dengan beberapa alternatif yang ada. Menjaga citra merek yang positif, terus meningkatkan kualitas produk merupakan beberapa faktor yang dapat menentukan keputusan pembelian konsumen.

Menurut Kotler dan Keller (2008: 346) citra merek adalah persepsi dan keyakinan yang dilakukan oleh konsumen, seperti tercermin dalam asosiasi yang terjadi dalam memori konsumen. Konsumen yang memiliki citra positif terhadap suatu merek, akan lebih memungkinkan untuk melakukan pembelian (Kotler, 2009:61). Disisi lain para produsen mobil harus terus melakukan inovasi terhadap produknya. Hal ini terlihat dari semakin beraneka ragamnya merek dan jenis mobil di Indonesia. Akibatnya konsumen harus semakin selektif dalam memilih produk yang akan dibeli. Kualitas produk di tentukan oleh atribut produk. Atribut produk adalah unsur-unsur produk yang dipandang penting oleh konsumen dan di jadikan dasar pengambilan keputusan pembelian (Tjiptono, 2009: 103). Semakin tinggi kualitas suatu produk, maka semakin tinggi keputusan konsumen untuk melakukan pembelian (Kotler, 2008).

Jumlah penjualan mobil merek Isuzu Panther PT. Astra Isuzu Semarang fluktuatif dan target penjualan yang tidak terpenuhi. Penjualan setiap tahunnya dalam empat tahun terakhir hanya pada tahun 2012 yang dapat melampui target yang telah ditetapkan. Dari penjualan mobil Isuzu Phanter, terjadi penurunan pada tahun 2013 dan 2015. Pada tahun 2015, penjualan juga mengalami penurunan yang sangat drastis dari tahun 2014. Terjadinya penurunan penjualan dan tidak tercapainya target penjualan yang telah ditetapkan menunjukkan turunnya minat konsumen terhadap mobil Isuzu Panther.

\section{Kajian Teori}

\section{Pemasaran}

Menurut William J. Stanton (dalam Usmara, 2008:7) pemasaran merupakan suatu sistem keseluruhan dari kegiatankegiatan usaha yang ditujukan untuk merencanakan, menentukan harga, mempromosikan, dan mendistribusikan barang dan jasa yang dapat memuaskan kebutuhan baik kepada pembeli yang ada maupun pembeli yang potensial.

\section{Perilaku Konsumen}

Menurut Ihalauw John (2005:11) adalah proses yang dilalui oleh seseorang dalam mencari, membeli, menggunakan, mengevaluasi dan bertindak pasca konsumsi produk, jasa maupun ide yang diharapkan bisa memenuhi kebutuhannya.

\section{Citra Merek}

Menurut Kotler dan Amstrong (2001:225) citra merek adalah seperangkat 
keyakinan konsumen mengenai merek tertentu.

\section{Kualitas Produk}

Menurut Kotler (2005:49) Kualitas produk adalah keseluruhan ciri serta dari suatu produk atau pelayanan pada kemampuan untuk memuaskan kebutuhan yang dinyatakan/ tersirat.

\section{Keputusan Pembelian}

Menurut Kotler (2003:143), keputusan pembelian merupakan perilaku atau tindakan sesorang untuk membeli atau menggunakan suatu produk baik berupa barang atau jasa yang telah diyakini akan memuaskan dirinya dan bersedia menanggung resiko yang mungkin terjadi.

\section{Hipotesis Penelitian}

Berdasarkan pada permasalahan yang telah diuraikan di atas dapat dirumuskan permasalahan sebagai berikut:

1. Apakah ada pengaruh citra merek terhadap keputusan pembelian mobil merek Isuzu Panther?

2. Apakah ada pengaruh kualitas produk terhadap keputusan pembelian mobil merek Isuzu Panther?

3. Apakah ada pengaruh citra merek dan kualitas produk terhadap keputusan pembelian mobil merek Isuzu Panther?

\section{Metodologi Penelitian}

Tipe penelitian yang digunakan dalam penelitian ini adalah merupakan tipe penelitian explanatory research. Metode pengumpulan data dalam penelitian ini menggunakan metode kuesioner dan wawancara dengan instrumen pengumpulan data berupa kuesioner. Skala pengukuran yang digunakan dalam penelitian ini adalah skala likert atau likert scale.

\section{Populasi dan Sampel}

Populasi dalam penelitian ini adalah konsumen yang telah membeli mobil merek Isuzu Panther pada PT. Astra Isuzu Semarang dari tahun 2012- 2015 dan bersedia di wawancarai. Jumlah sampel dalam penelitian ini adalah 72 responden. Teknik pengambilan sampel yang digunakan adalah non probability sampling dengan teknik purposive sampling.

\section{Analisis Tabulasi Silang}

Menurut Imam Ghozali (2005 : 21), analisis ini pada prinsipnya menyajikan data dalam bentuk tabulasi yang meliputi baris dan kolom. Analisis ini digunakan untuk mengetahui presentase kecenderungan antara variabel independen terhadap variabel dependen.

\section{Koefisien Determinasi}

Mengukur seberapa jauh kemampuan model dalam menerangkan variasi variabel dependen. Peneliti menggunakan nilai Adjusted $R$ Square pada saat mengevaluasi mana model regresi yang terbaik.

\section{Analisis Regresi Sederhana}

Untuk mengetahui pengaruh langsung masing-masing variabel bebas (Citra Merek dan Kualitas Produk) terhadap variabel terikat (Keputusan Pembelian).

\section{Analisa Regresi Berganda}

Untuk mengetahui pengaruh (Citra Merek dan Kualitas Produk) secara bersama-sama terhadap variabel terikat (Keputusan Pembelian), maka digunakan analisis regresi linear berganda.

\section{Uji T}

Uji t digunakan untuk menunjukkan seberapa jauh pengaruh satu variabel independen secara individual dalam menerangkan variasi variabel dependen. Ini berarti uji $t$ digunakan untuk menguji signifikansi hubungan antar variabel independen (Ghozali, 2005: 30). 


\section{Uji F}

Uji $\mathrm{F}$ pada dasarnya menunjukkan semua variabel bebas yang dimasukkan dalam model regresi mempunyai pengaruh secara bersama-sama terhadap variabel terikat (Ghozali, 2005: 44).

\section{Hasil}

\begin{tabular}{|c|c|c|c|c|}
\hline \multirow[b]{2}{*}{ Uji Hipotesis } & \multicolumn{4}{|c|}{ Hasil } \\
\hline & $\begin{array}{c}\text { Determi } \\
\text { nasi } \\
\end{array}$ & t Hitung & $\begin{array}{l}\mathrm{t} \\
\text { Hitung }\end{array}$ & $\begin{array}{c}\text { Keterangan } \\
\text { Hipotesis }\end{array}$ \\
\hline $\begin{array}{l}\text { 1.Terdapat } \\
\text { pengaruh positif } \\
\text { antara citra merek } \\
\text { terhadap } \\
\text { keputusan } \\
\text { pembelian mobil } \\
\text { merek Isuzu } \\
\text { Panther } \\
\text { 2. Terdapat } \\
\text { pengaruh } \\
\text { positif antara citra } \\
\text { merek } \\
\text { terhadap keputusan } \\
\text { pembelian mobil } \\
\text { merek } \\
\text { Isuzu Panther }\end{array}$ & $\begin{array}{l}16,9 \% \\
14,1 \%\end{array}$ & 3,552 & - & $\begin{array}{l}\text { Ha } \\
\text { diterima }\end{array}$ \\
\hline $\begin{array}{l}\text { 3. Terdapat } \\
\text { pengaruh } \\
\text { positif antara citra } \\
\text { merek } \\
\text { dan kualitas produk } \\
\text { terhadap keputusan } \\
\text { pembelian mobil } \\
\text { merek } \\
\text { Isuzu Panther }\end{array}$ & $22,7 \%$ & - & 11.419 & $\begin{array}{l}\mathrm{Ha} \\
\text { diterima }\end{array}$ \\
\hline
\end{tabular}

Sumber : Data primer yang diolah, 2015

\section{Pembahasan}

Berdasarkan hasil perhitungan dapat diketahui bahwa seluruh nilai t hitung dari setiap variabel $>\mathrm{t}$ tabel $(1,6669)$. Hasil pengujian uji $\mathrm{F}$ menunjukkan bahwa terdapat pengaruh antara variabel citra merek dan kualitas produk terhadap keputusan pembelian dengan nilai $\mathrm{F}$ hitung $>\mathrm{F}$ tabel $(3,979)$. Dari hasil uji regresi koefisien beta variabel citra merek lebih besar pengaruhnya yaitu sebesar $(0,391)$ dengan signifikansi $\quad(0,00<0,05)$ dibandingkan dengan variabel kualitas produk sebesar $(0,186)$ dengan signifikansi
$(0,01<0,05)$. Berdasarkan hasil analisis tabulasi silang kecenderungan hubungan antara citra merek mobil Isuzu Panther dengan keputusan pembelian yaitu pada variabel citra merek yang termasuk dalam kategori baik dengan total sebesar $65,3 \%$. Apabila diperhatikan secara cermat, kategori baik terdistribusikan pada keputusan pembelian yang tinggi sebesar $38,9 \%$. Serta kecenderungan hubungan antara kualitas produk mobil Isuzu Panther dengan keputusan pembelian yaitu pada variabel kualitas produk yang termasuk dalam kategori baik dengan total sebesar $68,1 \%$. Apabila diperhatikan secara cermat, kategori baik terdistribusikan pada keputusan pembelian yang tinggi sebesar 40,3 .

\section{Kesimpulan dan Saran}

\section{Kesimpulan}

Berdasarkan penelitian mengenai pengaruh citra merek dan kualitas produk terhadap keputusan pembelian mobil merek Isuzu Panther dapat disimpulkan sebagai berikut:

1. Variabel citra merek Isuzu Panther yang dipersepsikan oleh konsumen adalah baik, hal tersebut ditunjukkan dengan tanggapan responden sebesar $65 \%$ yang menyatakan baik, dan terdapat juga $26 \%$ responden yang menyatakan sangat baik. Hal ini dikarenakan bahwa citra merek dari mobil Isuzu Panther yang baik, sehingga dapat menarik perhatian konsumen, Isuzu Panther memberikan manfaat dalam penggunaannya, serta Isuzu Panther memiliki keiritan bahan bakarnya. Namun, terdapat responden yang menyatakan belum cukup baik dalam hal kurangnya rasa bangga dan kesan yang modern saat mengendarai mobil Isuzu Panther serta kurangnya rasa aman pada mobil Isuzu Panther ketika dikendarai karena nilai rata-rata indikatornya berada di bawah nilai rata-rata. 
2. Variabel kualitas produk Isuzu Panther yang dipersepsikan oleh konsumen adalah baik, hal tersebut ditunjukkan dengan tanggapan responden sebesar $68 \%$ yang menyatakan baik, dan terdapat juga $24 \%$ responden yang menyatakan sangat baik. Kualitas produk yang diterapkan pada mobil Isuzu Panther terbilang baik dibuktikan oleh banyaknya responden yang menyatakan bahwa memiliki bagian dalam yang luas serta kelengkapan fitur AC sehingga memberikan kenyamanan saat dikendarai, ketangguhan kondisi mobil dalam segala macam cuaca serta kekuatan mesin untuk digunakan dalam jalan tanjakan dan jarak jauh, kinerja sesuai dengan spesifikasi, memiliki plat body yang daya tahannya lamadan tampilan fisik atau desain mobil Isuzu Panther. Meskipun begitu, ada sebagian kecil responden yang beranggapan bahwa kualitas produkyang diberikan perusahaan belum cukup baik dalam aspek mengenai kinerja mesin yang dimiliki Isuzu Panther yang dirasa kurang, kurang lengkapnya fitur interior yang dimiliki Isuzu Panther, serta kualitas cat warna mobil Isuzu Panther dan keragaman warna mobil Isuzu Panther yang diangggap belum sesuai dengan keinginan karena nilai rata-rata indikatornya berada di bawah nilai rata-rata.

3. Variabel keputusan pembelian Isuzu Panther tergolong baik ditunjukkan dengan $60 \%$ terdistribusi pada kategori baik. Hal ini terjadi karena responden merasa pemilihan merek mobil Isuzu Panther yang menjadi prioritas pilihan utama yang dapat memenuhi kebutuhannya, keyakinan konsumen saat akan membeli mobil merek Isuzu Panther adalah mantap serta tingkat keinginan konsumen untuk merekomendasikan mobil Isuzu Panther kepada pihak lain juga tinggi. Walaupun masih ada sebagian kecil responden yang tidak memberikan penilaian yang tinggi. Kondisi tersebut dapat dilihat dari mempertimbangkan faktor kebutuhan serta waktu dalam pengambilan keputusan untuk membeli mobil Isuzu Panther. Pembelian mobil merupakan jenis pembelian yang termasuk jarang dibeli oleh karena itu perlunya tingkat keterlibatan konsumen dalam pembelian agar keputusannya tidak tergolong asal beli yang mungkin dapat disesali di kemudian hari.

4. Variabel citra merek secara parsial berpengaruh positif terhadap variabel keputusan pembelian sebesar $18 \%$. Variabel citra merek berpengaruh positif terhdap keputusan pembelian mobil Isuzu Panther dengan nilai koefisien regresi sebesar 0,391dengan nilai konstantanya adalah 6,994. Artinya apabila variabel citra merek ditingkatkan, maka variabel keputusan pembelian juga akan meningkat. Selain itu citra merek secara parsial berpengaruh signifikan terhadap keputusan pembelian yang dibuktikan dengan uji $\mathrm{t}$ (one tail) dengan nilai $\mathrm{t}$ hitung sebesar $(3,926)>t$ tabel $(1,667)$ dengan taraf signifikansi $5 \%$ pengaruh signifikan menunjukkan bahwa baik buruknya citra merek dapat dibuktikan secara nyata dapat mempengaruhi tinggi rendahnya keputusan pembelian.

5. Variabel kualitas produk secara parsial berpengaruh positif terhadap variabel keputusan pembelian sebesar $15 \%$. Variabel kualitas produk berpengaruh positif terhdap keputusan pembelian mobil Isuzu Panther dengan nilai koefisien regresi sebesar 0,186 dengan nilai konstantanya adalah 8,242. Artinya apabila variabel kualitas produk ditingkatkan, maka variabel keputusan pembelian juga akan meningkat. Sedangkan kualitas produk secara parsial berpengaruh signifikan terhadap keputusan pembelian yang dibuktikan dengan uji $\mathrm{t}$ (one tail) 
dengan nilai t hitung sebesar $(3,552)>$ $\mathrm{t}$ tabel $(1,667)$ dengan taraf signifikansi $5 \%$ pengaruh signifikan menunjukkan bahwa baik buruknya kualitas produk dapat dibuktikan secara nyata dapat mempengaruhi tinggi rendahnya keputusan pembelian.

6. Variabel citra merek dan kualitas produk secara simultan memiliki pengaruh positif terhadap variabel keputusan pembelian, yang ditunjukkan dengan nilai koefisien regresi variabel citra merek sebesar 0,304 dan variabel kualitas produk sebesar 0,132 dengan nilai konstantanya sebesar 1,881. Sedangkan, variabel citra merek dan kualitas produk secara simultan berpengaruh signifikan terhadap keputusan pembelian yang dibuktikan dengan uji F (one tail) sebesar 11,419 dengan taraf signifikansi 5\%. Pengaruh signifikan menunjukkan bahwa baik buruknya citra merek dan kualitas produk bersama-sama secara nyata dapat mempengaruhi tinggi rendahnya keputusan pembelian.

\section{Saran}

Berdasarkan hasil penelitian yang diperoleh, maka saran yang dapat disampaikan adalah sebagai berikut:

1. Berkaitan dengan variabel citra merek, pelanggan menilai bahwa adanya kekurangan pada aspek rasa aman pada saat berkendara. Hal ini menunjukkan bahwa Astra Isuzu perlu meningkatkan dengan memberikan teknologiteknologi terbaru khususnya dalam fitur keamanannya. Selain itu melalui penilaian pelanggan juga disebutkan bahwa adanya kekurangan pada aspek rasa bangga ketika mengendarai dan memiliki kesan modern ketika mengendarai mobil Isuzu Panther. Hal ini menunjukkan bahwa Astra Isuzu perlu meningkatkan perbaikan dan inovasi terhadap tampilan fisik atau desain mobil Isuzu Panther agar terlihat lebih menarik di mata konsumen, agar konsumen merasa lebih bangga dan memiliki kesan modern ketika mengendarai Isuzu Panther.
2. Berkaitan dengan variabel kualitas produk, pelanggan menilai bahwa adanya kekurangan pada aspek kinerja produk yaitu sering menemukan kendala yang dimiliki kinerja Isuzu Panther pada saat pengereman yang dirasa kurang pakem, tarikan gas yang dirasa berat serta kecepatan laju yang dirasa lambat. Hal ini menunjukkan bahwa Astra Isuzu perlu meningkatkan kualitas produk supaya lebih baik lagi dan memperbaiki kualitas kinerja produk seperti akselerasi yang lebih baik agar dapat melalui segala medan jalan. Selain itu melalui penilaian pelanggan juga disebutkan bahwa adanya kekurangan pada kelengkapan fitur yang dimiliki Isuzu Panther. Hal ini menunjukkan bahwa Astra Isuzu perlu meningkatkan perbaikan fitur yang dimiliki Isuzu Panther dan menambah fasilitas eksterior dan interior yang menarik sehingga memberikan nilai yang berbeda dari pada produk lain. Disamping itu melalui penilaian pelanggan juga disebutkan bahwa adanya kekurangan pada aspek umur ekonomis warna dan keragaman warna yang dimiki Isuzu Panther. Hal ini menunjukkan bahwa Astra Isuzu perlu meningkatkan kualitas bahan catnya agar awet dan tahan lama serta dari segi keragaman warna, perlu ditambah warna-warna yang mencolok seperti yang ada pada pesaingnya, karena ada beberapa responden yang menyukai warna mencolok.

\section{Daftar Referensi}

Armstrong, dan Kotler 2003, Dasar-dasar Pemasaran, Jilid 1, Edisi Kesembilan,. Penerbit PT.Indeks Gramedia, Jakarta.

Angipora, Marius. 2002. Dasar-Dasar Pemasaran. Edisi Kedua. PT. Raja Grafindo Persada. Jakarta.

Bilson, Simamora, 2004, Riset Pemasaran, Jakarta, Gramedia Utama Buchari, 
Alma. 2008. Public Relation sebagai Pengantar. Jakarta: Airlangga. Canon, Joseph. P, $d k k$, 2008. Pemasaran Dasar, Buku I Edisi 16. Salemba Empat.

Dharmmesta dan Irawan, 2000. Manajemen Pemasaran Modern, Edisi II, Liberty, Yogyakarta.

Durianto, Sugiarto dan Tony Sitinjak, 2001. Strategi Menaklukkan Pasar Melalui Riset Ekuitas dan Perilaku Merek. PT. Gramedia Pustaka, Jakarta.

Ghozali, Imam. 2006. Analisis Multivariate Lanjutan dengan Program SPSS. Semarang: Badan Penerbit Universitas Diponegoro.

Ghozali, Imam, 2009. Aplikasi Analisis Multivariate dengan Program SPSS, Edisi. Keempat, Penerbit Universitas Diponegoro.

Ghozali, Imam. 2011. Aplikasi Analisis Multivariate dengan Program SPSS. Semarang: Badan Penerbit Universitas Diponegoro.

Hendra Noky Adrianto, Idris. 2013. Pengaruh Kualitas Produk, Citra Merek, Harga dan Promosi Terhadap Keputusan Pembelian Mobil Merek Toyota Kijang Innova di Semarang. Skripsi. Universitas Diponegoro

J.Supranto. 2001. Statistik teori dan aplikasi. Edisi 6. Jakarta : Erlangga

Keller, Kevin Lane. 1998. Strategic Brand Management: Building, Measuring, and Managing Brand Equity, Prentice Hall, New Jersey.

Kotler dan Amstrong. (2004). Prinsipprinsip Marketing, Edisi Ketujuh. Penerbit Salemba

Kotler, Philip. 2005. Manajemen Pemasaran. Jilid II. Edisi Kesebelas. Alih Bahasa Benyamin Molan. Jakarta : Indeks
Kotler dan Keller. 2009. Manajemen Pemasaran. Jilid I. Edisi ke 13. Jakarta: Erlangga

Kotler, Philiph danAmstrong, Gary. 2006. Prinsip-prinsip Pemasaran. Jakarta: Erlangga

Kotler dan Keller. 2007. Manajemen Pemasaran, Edisi 12, Jilid 1. Jakarta: PT. Indeks.

Kotler dan Keller. 2009. Manajemen Pemasaran. Jilid I. Edisi ke 13. Jakarta: Erlangga

Kotler, Philip. 2002. Manajemen Pemasaran, Jilid 1, Edisi Milenium. Jakarta

Kotler, Philip. 2000. Manajemen Pemasaran, Edisi Milenium. Jakarta

Kotler, Philip dan Gary Amstrong. 2001. Prinsip-prinsip Pemasaran. Penerjemah Imam Nurmawan. Jakarta: Penerbit Salemba Empat

Kotler dan Amstrong. 2008. Manajemen Pemasaran. Jilid I. Jakarta: PT. Indeks

Kotler, Philip and Amstrong. 1997. Prinsipprinsip Pemasaran (edisi ketiga). Jakarta: Erlangga.

Lamb, Charles W.,Hair, Joseph F., dan Mc Daniel . 2001. Pemasaran Buku I. Jakarta: Salemba Empat

Lupiyoadi, Rambat dan A.Hamdani (2006). Manajemen Pemasaran Jasa, Edisi Kedua, Jakarta:Salemba Empat

Prasetijo, Ristiyanti dan John Ihalauw. 2005. Perilaku Konsumen. Yogyakarta: Penerbit Andi

Putra, Arya Willis. 2015. Pengaruh Kualitas Produk, Citra Merek dan Harga Terhadap Keputusan Pembelian Mobil Merek Toyota Avanza. Skripsi. Universitas Diponegoro.

Rangkuti, Freddy. 2002. Riset Pemasaran. Jakarta : PT. Gramedia Pustaka Utama 
Ridhwan, Ria Maharani. 2014. Pengaruh Citra Merek dan Kualitas Produk Terhadap Keputusan Pembelian Mobil Honda All New Jazz. Skripsi. Universitas Brawijaya

Rumengan , Aveline N. 2015. Analisis Citra Merek, Kualitas Produk, dan Strategi HargaTerhadap Keputusan Pembelian Mobil Daihatsu Ayla Cabang Manado. Journal Emba. Universitas Sam Ratulangi

Schiffman, Leon, \& Kanuk, Leslie Lazar. 2008. Consumer Behaviour 7th Edition (Perilaku Konsumen). Jakarta: PT. Indeks

Setiadi, Nugroho. 2003. Perilaku Konsumen : Konsep dan Implikasi untuk Strategi dan

Penelitian Pemasaran. Prenada Media : Jakarta.

Simamora, Bilson. 2001. "Remarkerting for Business Recovery, Sebuah Pendekatan Riset".

Jakarta: Gramedia PU.

Sugiyono. 1999. Metode Penelitian Bisnis. Bandung: Penerbit Alfabeta.

Sugiyono. 2004. Metode Penelitian Bisnis. Bandung: Penerbit Alfabeta.

Sugiyono. 2006. Metode Penelitian Bisnis. Bandung: Penerbit Alfabeta.

Sugiyono. 2008. Metode Penelitian Bisnis. Bandung: Penerbit Alfabeta.

Sugiyono. 2009. Metode Penelitian Kuantitatif, Kualitatif, Research, dan Development.

Bandung: Penerbit Alfabeta.

Sugiyono. 2010. Metode Penelitian Bisnis, Bandung: Penerbit Alfabeta.

Sumarwan, Ujang. 2003. Perilaku Konsumen. Penerbit Ghalia Indonesia, Jakarta.

Sutisna. 2003. Perilaku Konsumen dan Komunikasi Pemasaran. PT Remaja Rosdakarya. Bandung
Sutisna dan Pawitra, 2001. Perilaku Konsumen dan Komunikasi Pemasaran, Bandung: Penerbit PT. Remaja Rosdakarya

Swastha, Basu dan Irawan. 1997. Manajemen Pemasaran Modern. Yogyakarta: Liberty.

Usmara, A, 2008. Strategi Baru Manajemen Pemasaran. Jakarta: Amara Books. 